\title{
The Expression of Ets-1 and c-Jun in Morphogenesis of Aortic Endothelial Cells in vitro
}

\author{
Y. C. Hsu* and V. C. Yang*
}

* Department of Biology, Tunghai University, 181, 3rd Section of Chung-Kang Rd. Taichung, Taiwan. R.O.C

Angiogenesis, the formation of new blood vessels, is essential in development, reproduction, and wound repair. In the presence of angiogenic stimuli, vascular endothelial cells (ECs) begin to degrade the underlying basement membrane and migrate toward the site of angigenic stimuli, then proliferate and differentiate to form sprouts of new vessels. Degradation of basement membrane and cell migration are regulated by the elaboration of matrix-degrading enzymes, including plasminogen activators, stromelysin, gelatinase, and collagenase. [1] It has been suggested that the increased elaboration of proteolytic activity by ECs an initiation step of the angiogenic processes; however, the mechanism underlying angiogenic factor-induced protease expression remain to be elucidated. Ets-1 and c-Jun are two important transcription factors in early angiogenesis. [2] In this study, the expression of metalloprotease transcription factors Ets-1 and c-Jun in TPA-induced morphogenesis of aortic Ecs are investigated by immunofluorescence microscopy and immunoblotting analysis.

The results show that when ECs growing in the collagen gel for $4 \mathrm{hr}$, the cells remain spherical. During $24 \mathrm{hr}$, cells become elongate and undergo morphogenesis. Seventy-two hr after being grown in collagen gel, ECs are organized around to form capillary-like tubular structures(Fig.1). ECs morphogenesis is accompanied by increase in the expression of Ets-1. The level of Ets-1 reach to the highest level at $24 \mathrm{hr}$ when the cell are elongated. When the cells start to form the tubular structures, the level of Ets-1 decreases. However the expression of c-Jun increases at $6 \mathrm{hr}$, and persists through $24 \mathrm{hr}$ and $48 \mathrm{hr}$, and decrease at $72 \mathrm{hr}$.

References

[1] Montesano, R. et al. J. Cell Biol. 97 (1983)1648-1652.

[2] Shono, T. et al. Mol. Cell Biol. 16 (1996) 4231-4239.

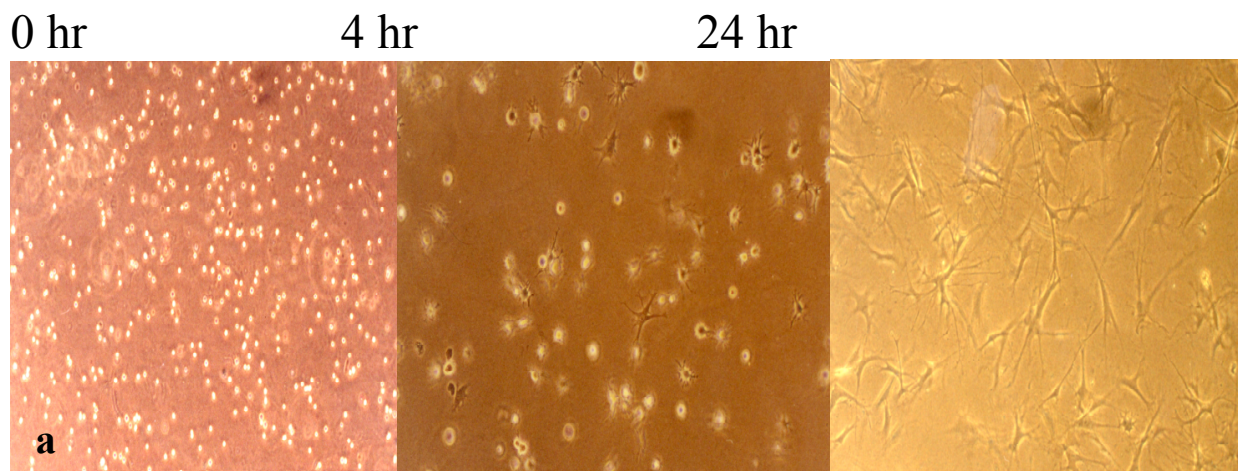



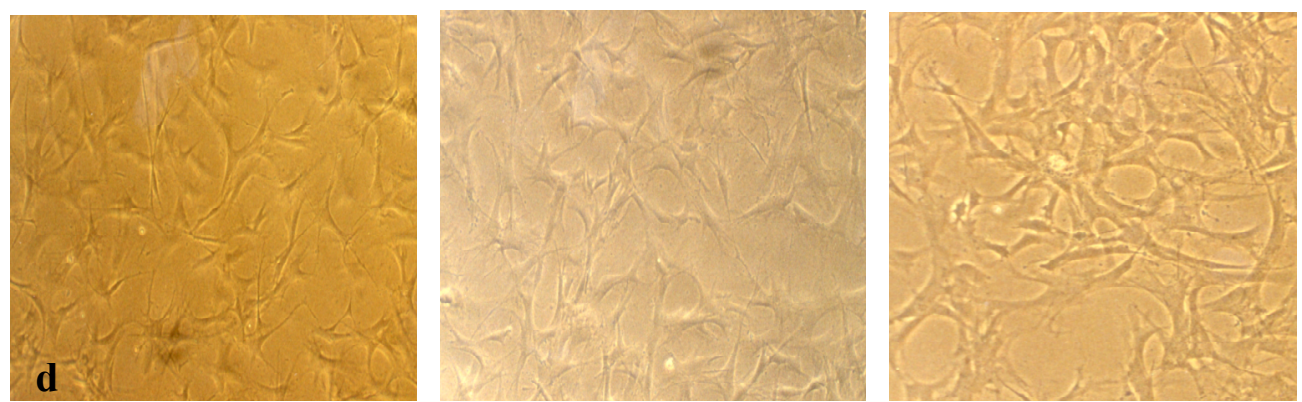

FIG.1 Rat aortic endothelial cells growing in collagen gel for $0,24,48,72,96 \mathrm{hr}$. At $24 \mathrm{hr}$ some cells start to elongate. At $48 \mathrm{hr}$, cells undergo morphogenesis. The cells were organized around to form capillary-like tubular structures. At $96 \mathrm{hr}$, cells were organized into a network of branching and anastomosing cords of endothelial cells.

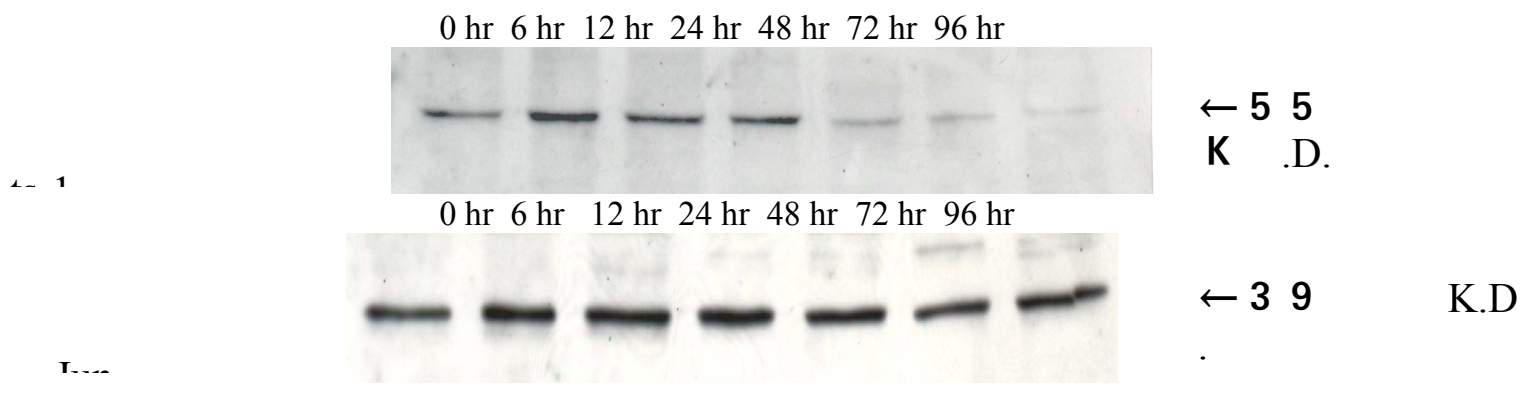

FIG.2 Western blotting of c-Jun and Ets-1. Endothelial cells growing in collagen gel at different stages. 